Check for updates

Cite this: RSC Adv., 2018, 8, 29958

\title{
Origin of the effects of PEG additives in electrolytes on the performance of quantum dot sensitized solar cells $\uparrow$
}

\begin{abstract}
Yu Sun, ${ }^{a}$ Guocan Jiang, ${ }^{a}$ Mengsi Zhou, ${ }^{a}$ Zhenxiao Pan*b and Xinhua Zhong (DD *ab
It has been well established that polymer additives in electrolyte can impede the charge recombination processes at the photoanode/electrolyte interface, and improve performance, especially $V_{o c}$, of the resulting sensitized solar cells. However, there are few reports about the effect of electrolyte additives on counter electrode (CE) performance. Herein, we systematically investigated the effect of polyethylene glycol (PEG) additives with various molecular weights ( $M_{w}$ from 300 to 20000 ) in polysulfide electrolyte on the performance of two representative $\mathrm{CdSe}$ and $\mathrm{Zn}-\mathrm{Cu}-\mathrm{In}-\mathrm{Se}$ (ZCISe) quantum dot sensitized solar cells (QDSCs), and explored the mechanism of the observed effects. Electrochemical impedance spectroscopy measurements indicate that all PEG additives can improve the charge recombination resistance at the photoanode/electrolyte interface, therefore suppressing the unwanted charge recombination process, and enhancing the $V_{\text {oc }}$ of the resulting cell devices accordingly. On the CE side, with the increase of $M_{w}$ of PEG additives, the initial effect of reducing the charge transfer resistance at the $\mathrm{CE} /$ electrolyte interface evolves into an increasing resistance; accordingly the initial positive effect on FF turns into negative one. Accordingly, low $M_{w}$ PEG can improve efficiency for both CdSe (increasing from $6.81 \%$ to $7.60 \%$ ) and ZCISe QDSCs (increasing from $9.26 \%$ to $10.20 \%$ ). High $M_{w}$ PEG is still effective for CdSe QDSCs with an efficiency of $7.38 \%$, but falls flat on ZCISe QDSCs (with an efficiency of $9.11 \%$ ).
\end{abstract}

Received 7th July 2018

Accepted 17th August 2018

DOI: $10.1039 / c 8 r a 05794 j$

rsc.li/rsc-advances

\section{Introduction}

Exploring photovoltaic cells with high efficiency and low cost is believed to be a promising way to solve the urgent energy and environment issues. ${ }^{1,2}$ Being a new type of photovoltaic cell, quantum dot sensitized solar cells (QDSCs) are attracting increasing research interest due to a variety of unique advantages of semiconductor QD light harvesting materials such as: high absorption coefficient, tunable light harvesting range, solution processability, high stability toward light, heat, and moisture, as well as high theoretical power conversion efficiency (PCE) due to multi-exciton generation possibilities. ${ }^{3-9}$ In the past several years, the reported highest PCE for QDSCs has been increased from less than $5 \%$ to over $12 \% .^{10-19}$ The enhancement of PCE for QDSCs has been achieved mainly through two approaches: (i) by exploring new types of counter electrode (CE),

${ }^{a}$ School of Chemistry and Molecular Engineering, East China University of Science and Technology, Shanghai 200237, China. E-mail: zhongxh@ecust.edu.cn

${ }^{b}$ College of Materials and Energy, South China Agricultural University, 483 Wushan Road, Guangzhou 510642, China.E-mail: zxpan@scau.edu.cn

$\dagger$ Electronic supplementary information (ESI) available: Detailed $J-V$ curves, photovoltaic performance parameters, and additional EIS Nyquist curves under different forward bias for each QDSCs under electrolyte solutions containing different PEG additives. See DOI: 10.1039/c8ra05794j mainly $\mathrm{Cu}_{2} \mathrm{~S} /$ brass and mesoporous carbon/titanium mesh CEs, to improve the fill factor $(\mathrm{FF})$, and open-circuit voltage $\left(V_{\mathrm{oc}}\right)$ of a cell device ${ }^{\mathbf{1 0 , 1 1 , 2 0 - 2 2}}$ (ii) by expanding the solar light harvesting range through the adoption of near infrared adsorption QD sensitizers, mainly Cd-Se-Te, and $\mathrm{Cu}-\mathrm{In}-\mathrm{Se}$ based QDs, and exploring effective QD sensitization methods to ensure high QD loading amount on $\mathrm{TiO}_{2}$ film electrodes to realize the full capture of solar light and the enhancement of short-circuit current $\left(J_{\mathrm{sc}}\right)$ from the aspect of photoanodes. ${ }^{12-19,23}$

Compared to the extensively studied photoanodes and CEs, the other vital component redox couple electrolyte is significantly less concerned. In fact, electrolyte plays the crucial role of QD regeneration and charge transfer between photoanode and $\mathrm{CE}$, which is critical in determining the photovoltaic performance of a cell device, especially $V_{\text {oc }}$ and FF values. ${ }^{24,25} \mathrm{Up}$ to date, polysulfide/sulfide $\left(\mathrm{S}_{n}{ }^{2-} / \mathrm{S}^{2-}\right)$ redox couple electrolyte is the most commonly used one in QDSCs since this electrolyte media can stabilize the commonly adopted QD light-absorbers, and enables effectively scavenging photo-induced holes to neutralize and regenerate oxidized QDs and make circulatory cells practicable. However, due to the undesirable high redox potential of $\mathrm{S}_{n}{ }^{2-} / \mathrm{S}^{2-}$ redox couple, a high overpotential is required for QD regeneration. This results in a relatively low $V_{\mathrm{oc}}$ value in the corresponding cell devices. ${ }^{10-19}$ In order to overcome this shortage, new redox couples, such as $\mathrm{I}^{-} / \mathrm{I}^{3-}, \mathrm{Co}^{2+/ 3+}$ 
complexes, and organic redox couples, have been exploited for QDSCs in recent years. ${ }^{26-32}$ Unfortunately, these redox couples failed in achieving better photovoltaic performance due to the incompatibility of QDs in these redox couple electrolyte media or the existence of severe unwanted charge recombination. Therefore, at current stage it is a wise strategy to modify electrochemical features of the conventional polysulfide electrolyte with introduction of suitable organic or inorganic additives. This strategy can usually bring forward three beneficial effects based on literature results: (i) improving $V_{\text {oc }}$ of the cells due to the adsorption of organic polymer on the surface of QD sensitized $\mathrm{TiO}_{2}$ film electrode and the formation of energetic barrier layer to impede the charge recombination processes occurring

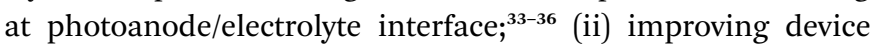
stability due to the gelation effect by the strong water-absorbing capacity of the polymer additives $;^{37-42}$ (iii) tuning the potential of redox couple, or even shifting the conduction band edge of the $\mathrm{TiO}_{2}$ substrate in the case of some small molecule additives. ${ }^{\mathbf{4 3 - 4 5}}$ However, there are few reports about the effect of electrolyte additives on the performance of CE in sensitized solar cells.

Herein, we systematically investigated the effects of polyethylene glycol (PEG) additives with various molecular weights ( $M_{\mathrm{w}}$ from 300 to 20000$)$ in polysulfide electrolyte on the performance of QDSCs and explored the origin of the observed effects. Two representative QDSCs, CdSe, and $\mathrm{Zn}-\mathrm{Cu}-\mathrm{In}-\mathrm{Se}$ (ZCISe), were used as the model device to evaluate these effects. It was found that all kinds of PEG additives have a positive effect on $V_{\mathrm{oc}}$ and $\mathrm{FF}$, negligible effect on $J_{\mathrm{sc}}$ value in CdSe QDSCs. In ZCISe QDSCs system, the positive effect on $V_{\text {oc }}$ by PEG additives was also realized, while with the increase of $M_{\mathrm{w}}$ of PEG, the positive or neutral effects on $\mathrm{FF}$ and $J_{\text {sc }}$ turned into negative ones gradually. Relying on the electrochemical impedance measurements, the effects of PEG additives on the performance of photoanodes and CEs, and therefore the influence on photovoltaic parameters of $V_{\mathrm{oc}}, J_{\mathrm{sc}}, \mathrm{FF}$, and PEC were explored. Furthermore, a facile and general route for remarkably improving photovoltaic performance of QDSCs was offered with introduction of low $M_{\mathrm{w}}$ PEG additives into the polysulfide electrolyte.

\section{Experimental section}

\section{QDs synthesis and cell device fabrication}

The oleylamine-capped $5.2 \mathrm{~nm}$ CdSe QDs, and $4.1 \mathrm{~nm}$ ZCISe QDs were synthesized according to literature method..8,35,46 Water-soluble mercaptopropionic acid (MPA) capped QDs were obtained via a ligand exchange process with use of MPA as phase transfer reagent. The $\mathrm{TiO}_{2}$ mesoporous film electrodes were prepared according to standard literature method. ${ }^{47}$ The water-soluble QDs were tethered on the $\mathrm{TiO}_{2}$ mesoporous film through the capping ligand induced self-assembly route by dipping the QD solution on the film and staying for a certain period. ${ }^{21}$ Thereafter, $\mathrm{ZnS}$, and $\mathrm{SiO}_{2}$ passivation layer were deposited on the QD sensitized $\mathrm{TiO}_{2}$ film electrodes and served as photoanodes. Sandwich structured cell devices were fabricated through assembling the photoanode, and $\mathrm{Cu}_{2} \mathrm{~S} /$ brass electrode CEs, and filling with electrolyte aqueous solutions with composition of $2.0 \mathrm{M} \mathrm{S}$ and $\mathrm{Na}_{2} \mathrm{~S}, 0.2 \mathrm{M} \mathrm{KCl}$, and different $M_{\mathrm{w}}$ PEG additives (i.e. $20 \mathrm{wt} \%$ for both PEG-300, and PEG-1K, $15 \mathrm{wt} \%$ for PEG-4K and $8 \mathrm{wt} \%$ for PEG-20K). For the reference sample, plain polysulfide/sulfide electrolyte without the existence of any PEG additives. To ensure the reliability of the data, 5 pieces of cells under each condition were fabricated and measured.

\section{Characterization}

The performance of QDSCs was tested using a Keithley 2400 source meter under the illumination of simulated AM1.5G solar light (Oriel, model no. 94022A) with intensity of $100 \mathrm{~mW} \mathrm{~cm}^{-2}$ ( 1 full solar light). The light intensity was calibrated by a NREL standard Si solar cell. The effective area of the cells was determined by a $0.235 \mathrm{~cm}^{2}$ black mask. The conductivity of the electrolyte solutions was tested by DDSJ-308A conductivity meter at $25{ }^{\circ} \mathrm{C}$. Electrochemical impedance spectroscopy (EIS) measurements were carried out on a Zennium electrochemical workstation (Zahner). The EIS spectra for a full solar cell were obtained under dark conditions at different forward bias ranging from -0.35 to $-0.65 \mathrm{~V}$, applying a $20 \mathrm{mV}$ AC sinusoidal signal over the constant applied bias with the frequency ranging from $1 \mathrm{MHz}$ to $0.1 \mathrm{~Hz}$. The EIS spectra and Tafel-polarization curves for symmetric dummy cells consisting of two identical $\mathrm{Cu}_{2} \mathrm{~S} /$ brass electrode were measured by applying a $20 \mathrm{mV} \mathrm{AC}$ sinusoidal signal over the constant applied bias with the frequency range of $100 \mathrm{mHz}$ to $100 \mathrm{kHz}$.

\section{Results and discussion}

\section{Influence of PEG molecular weight of on the cell performance}

According to our previous results, high molecular weight $\left(M_{\mathrm{w}}\right)$ PEG modifying polysulfide electrolytes can improve the photovoltaic performance of CdSe QDSCs, but fails flat for ZCISe QDSCs. ${ }^{31}$ In this work, we systematically studied the influence of PEG additives with different $M_{\mathrm{w}}$ on the photovoltaic performance of the most commonly studied CdSe and ZCISe QDSCs. On the other hand, the selected ZCISe QDSCs exhibit best performance among all kind of QDSCs. ${ }^{\mathbf{1 8 , 1 9 , 3 5}}$ Commercially available PEG with $M_{\mathrm{w}}$ of 300, 1000, 4000, and 20000 (noted as PEG-300, PEG-1K, PEG-4K, and PEG-20K, respectively henceforth) were selected and evaluated in this study. QDSC cell devices were constructed according to literature method by assembling QD sensitized photoanodes and $\mathrm{Cu}_{2} \mathrm{~S} /$ brass CEs. ${ }^{15,35,47}$ Electrolyte solutions were derived from conventional polysulfide/sulfide aqueous solution electrolyte with addition of optimum weight fractions of different PEG additives. Detailed procedure for the fabrication and measurement of QDSCs can be found in the Experimental section. Under each condition, five cells were fabricated and measured in parallel, and the average values were used in the evaluation of the photovoltaic performance in order to ensure the validity of the reported results.

First, optimum concentrations for all selected PEG additives in polysulfide electrolyte were determined, and the corresponding $J-V$ curves are illustrated in Fig. S1 of the ESI. $\dagger$ 
Experimental results indicate that the optimum concentration range for low $M_{\mathrm{w}}$ PEG-300, and PEG-1K is located in 20-30 wt\%. While for high $M_{\mathrm{w}}$ PEG-4K and PEG-20K, their optimum concentrations correspond to their corresponding highest solubility in this electrolyte solution, i.e. $15 \mathrm{wt} \%$ and $8 \mathrm{wt} \%$, respectively. Correspondingly, in the following experiments, $25 \mathrm{wt} \%$ was chosen for PEG-300, and PEG-1K, while $15 \mathrm{wt} \%$ for PEG-4K, and $8 \mathrm{wt} \%$ for PEG-20K. After that, cell performances corresponding to polysulfide electrolyte containing different PEG additives under their optimum concentrations were measured together with reference sample without any PEG additives in polysulfide electrolyte. The detailed $J-V$ curves and corresponding extracted main photovoltaic parameters $\left(V_{\mathrm{oc}}, J_{\mathrm{sc}}\right.$, FF, and PCE,) are available in Fig. S2, S3, Tables S1 and S2. $\dagger$

Fig. 1 illustrates the dependence of main photovoltaic parameters on polysulfide electrolyte containing different PEG additives for both CdSe and ZCISe QDSC systems, and the detailed average photovoltaic parameters are summarized in Tables 1 and 2. From Fig. 1a, d, Tables 1 and 2, we can find that all kinds of PEG additives in polysulfide electrolyte can enhance $V_{\text {oc }}$ values for both CdSe and ZCISe cells in comparison with reference samples without any PEG additives (in CdSe cells, $V_{\text {oc }}$ improving from $0.65 \mathrm{~V}$ to $0.68-0.69 \mathrm{~V}$; in ZCISe cells, $V_{\mathrm{oc}}$ improving from $0.59 \mathrm{~V}$ to $0.62-0.63 \mathrm{~V}$ ). In the case of $J_{\text {sc }}$ parameter, the effects of PEG additives for CdSe and ZCISe QDSCs are different. All PEG additives have negligible effects on CdSe QDSCs (the $J_{\text {sc }}$ value keeping nearly constant in
Table 1 Average photovoltaic performance of CdSe QDSCs with different PEG additives modified electrolyte under AM 1.5G illumination

\begin{tabular}{lrlll}
\hline PEG additives & $J_{\text {sc }}\left(\mathrm{mA} \mathrm{cm}^{-2}\right)$ & $V_{\text {oc }}(\mathrm{V})$ & FF $(\%)$ & PCE $(\%)$ \\
\hline Ref. & $15.81 \pm 0.17$ & $0.654 \pm 0.005$ & $66.0 \pm 0.8$ & $6.81 \pm 0.11$ \\
PEG-300 & $15.72 \pm 0.15$ & $0.688 \pm 0.007$ & $69.7 \pm 1.1$ & $7.54 \pm 0.11$ \\
PEG-1K & $15.8 \pm 0.20$ & $0.691 \pm 0.005$ & $69.6 \pm 0.9$ & $7.60 \pm 0.05$ \\
PEG-4K & $15.84 \pm 0.12$ & $0.685 \pm 0.005$ & $68.8 \pm 0.6$ & $7.50 \pm 0.04$ \\
PEG-20K & $15.83 \pm 0.17$ & $0.685 \pm 0.006$ & $68.3 \pm 0.4$ & $7.38 \pm 0.07$
\end{tabular}

a narrow range of $15.68-15.84 \mathrm{~mA} \mathrm{~cm}^{-2}$ ). While for ZCISe QDSCs, low $M_{\mathrm{w}}$ PEG (PEG-300, and PEG-1K) additives have insignificant effects on $J_{\text {sc }}$, but high molecular weight PEG (PEG-4K and PEG-20K) additives have slightly negative effects on it (decreasing from 26.55 to 26.02 , and $25.55 \mathrm{~mA} \mathrm{~cm}^{-2}$, respectively). For the FF value, low $M_{\mathrm{w}}$ PEG additives (PEG-300 and PEG-1K) have positive effect for both CdSe and ZCISe QDSCs (in CdSe, improving from $66.0 \%$ to $68.8-69.1 \%$; in ZCISe, improving from $59.0 \%$ to $61.1 \%$, and $60.8 \%$ ); high $M_{\mathrm{w}}$ PEG (PEG-4K and PEG-20K) additives still have positive effects for CdSe cells (improving to 68.3\%, and 68.8\%, respectively), but negative effects for ZCISe cells (decreasing the FF value to $58.5 \%$, and $55.6 \%$, respectively). Correspondingly, for PCE value, all PEG additives have positive effect without significant difference for CdSe QDSCs in comparison with reference samples (improving from $6.81 \%$ to $7.38-7.60 \%$ ); for ZCISe
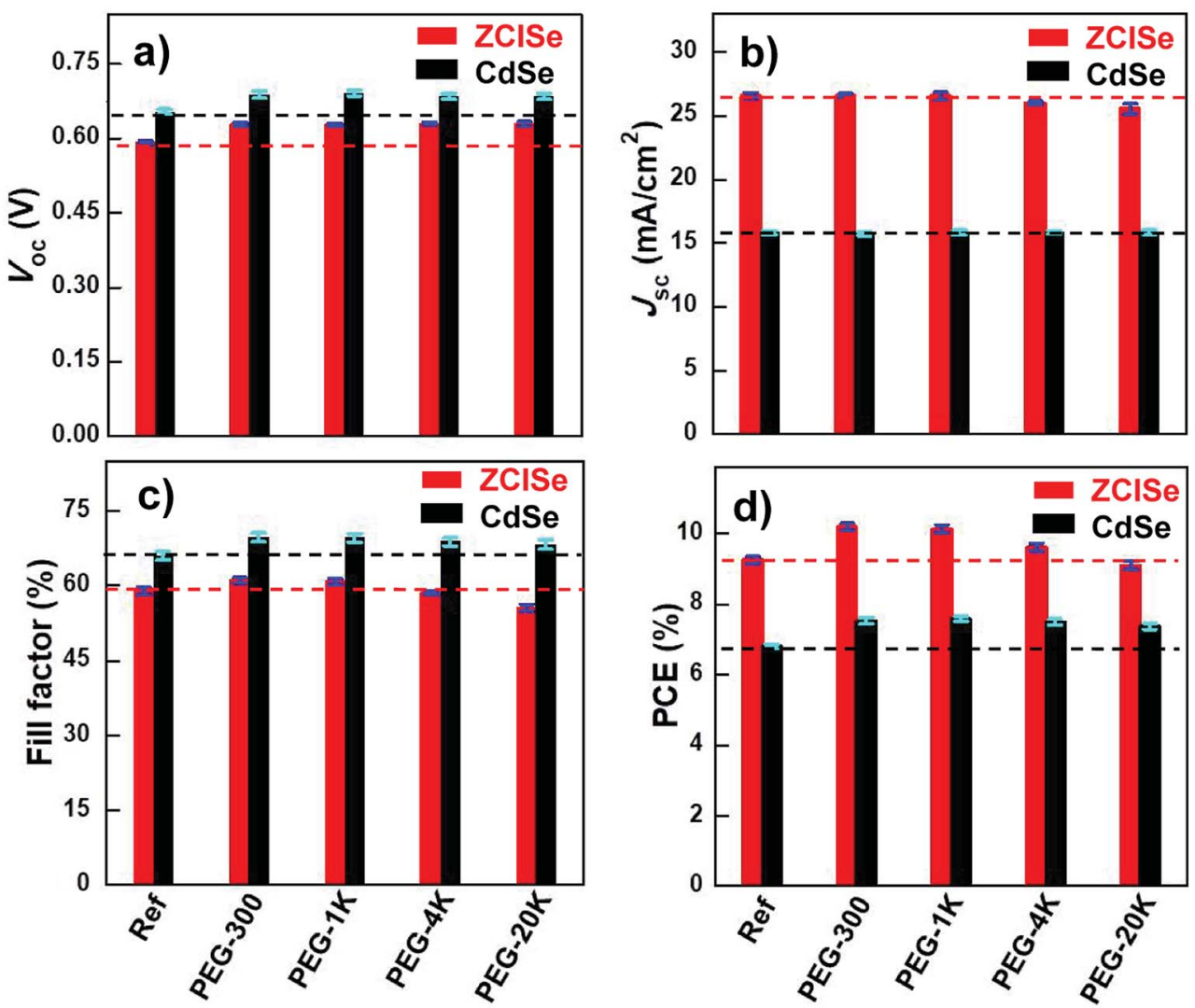

Fig. 1 The dependence of photovoltaic parameters: (a) PCE, (b) $V_{\mathrm{oc}}$, (c) $J_{\mathrm{sc}}$, and (d) FF, on PEG additives with different molecular weights in polysulfide electrolyte in ZCISe and CdSe QDSCs. 
Table 2 Average photovoltaic performance of ZCISe QDSCs with different PEG additives modified electrolyte under AM 1.5G illumination

\begin{tabular}{|c|c|c|c|c|}
\hline PEG additives & $J_{\mathrm{sc}}\left(\mathrm{mA} \mathrm{cm}{ }^{-2}\right)$ & $V_{\mathrm{oc}}(\mathrm{V})$ & $\mathrm{FF}(\%)$ & PCE (\%) \\
\hline Ref. & $26.55 \pm 0.23$ & $0.591 \pm 0.004$ & $58.96 \pm 0.7$ & $9.26 \pm 0.10$ \\
\hline PEG-300 & $26.58 \pm 0.18$ & $0.629 \pm 0.003$ & $61.06 \pm 0.7$ & $10.20 \pm 0.09$ \\
\hline PEG-4K & $26.03 \pm 0.12$ & $0.630 \pm 0.003$ & $58.6 \pm 0.4$ & $9.62 \pm 0.03$ \\
\hline PEG-20K & $25.55 \pm 0.42$ & $0.630 \pm 0.004$ & $56.6 \pm 0.7$ & $9.11 \pm 0.12$ \\
\hline
\end{tabular}

QDSCs, with the increase of $M_{\mathrm{w}}$ of PEG additive, the extent of improving PEC value decreases systematically. In detail, low $M_{\mathrm{w}}$ PEG-300, and PEG-1K can remarkably improve the PEC of ZCISe QDSCs from $9.26 \%$ to $10.20 \%$, and $10.14 \%$, respectively, while PEG-4K can only slightly enhance the PEC value to 9.62\%; inversely, PEG-20K even has negative effect and decrease the value to $9.11 \%$. In summary, low $M_{\mathrm{w}}$ PEG-300 and PEG-1K can serve as a general photovoltaic performance enhancement additive for the representative CdSe and ZCISe QDSCs. High $M_{\mathrm{w}}$ PEG, especially PEG-20K, can only improve the performance of CdSe QDSCs, but fails flat in ZCISe cells due to the negative effects on $\mathrm{FF}$ and $J_{\mathrm{sc}}$.

\section{Impedance spectroscopy of full cell devices}

In order to unravel the intrinsic mechanism for the influence of different PEG additives in polysulfide/sulfide electrolyte on the photovoltaic performance of CdSe and ZCISe QDSCs, electrochemical impedance spectroscopy (EIS) for a full cell device was employed. This is because EIS is a well-established technique to distinguish the electrochemical features corresponding to different constituents in a cell device. ${ }^{4849}$ EIS measurements were carried out under dark condition with forward bias voltage in a range from -0.35 to $-0.65 \mathrm{~V}$ by applying a $20 \mathrm{mV}$ AC sinusoidal signal in a frequency range of $100 \mathrm{kHz}$ to $0.1 \mathrm{~Hz}$. Nyquist curves for each QDSCs corresponding to different electrolyte systems under different bias are available in Fig. S4-S6.† Main EIS parameters including series resistance $\left(R_{\mathrm{S}}\right)$, chemical capacitance $\left(C_{\mu}\right)$ and charge recombination resistance $\left(R_{\text {rec }}\right)$ were deduced from the EIS curves with use of a standard simulation circuit as reported in literature. ${ }^{47}$ It is noted that chemical capacitance $\left(C_{\mu}\right)$ stands for the change of electron density as a function of Fermi level, and the parameter charge recombination resistance $\left(R_{\text {rec }}\right)$ corresponds to the charge recombination resistance at the photoanode/electrolyte interfaces. ${ }^{\mathbf{4 8 , 4 9}}$ The applied bias $\left(V_{\text {app }}\right)$ dependent chemical capacitance, and charge recombination resistance values were illustrated in Fig. 2.

From Fig. 2a and d, we can find that in both CdSe and ZCISe QDSCs, the extracted $C_{\mu}$ values exhibit a near linear relationship to the forward bias voltage in each electrolyte system, and all these curves are overlapped together. This means that cell devices with different electrolyte systems show ignorable variation in the obtained $C_{\mu}$ values. This indicates that the introduction of PEG additives in the initial polysulfide electrolyte solution does not alter the conduction band edge or the electron density of the states of $\mathrm{TiO}_{2}$ matrix. ${ }^{48-50}$ This result is also in accordance with previous reports, ${ }^{34,37,38}$ wherein other water- soluble polymers such as poly(vinylpyrrolidone) (PVP), sodium carboxymethylcellulose (CMC-Na), and sodium polyacrylate (PAAS) were used as additives to modify the polysulfide/sulfide electrolyte in the construction of QDSCs. ${ }^{34,37,38}$ However, from Fig. $2 \mathrm{~b}$ and e it can be found that with the increase of $M_{\mathrm{w}}$ of PEG additives in electrolyte solutions, the obtained $R_{\text {rec }}$ values enhance systematically, and the $R_{\text {rec }}$ values exhibit a near linear relationship to the forward bias in each electrolyte system. For clarity, Nyquist plots of cell devices under forward bias near the $V_{\text {oc }}$ value (herein of $-0.65 \mathrm{~V}$ ) are shown in Fig. $2 \mathrm{c}$ and $\mathrm{f}$. Accordingly, the extracted EIS parameters based on these plots are listed in Table 3. We can find that accompanying with the increase of $M_{\mathrm{w}}$ of PEG additives in the electrolyte, the diameter of the EIS semicircles increases systematically. This indicates that with the presence of PEG additives, the $R_{\text {rec }}$ value at photoanode/electrolyte interface are improved accordingly, and the effect is strengthened systematically with the increase of $M_{\mathrm{w}}$ of PEG additives. As listed in Table 3, we can find that the $R_{\text {rec }}$ value of the PEG modified electrolyte system is increased systematically in both CdSe and ZCISe QDSC systems (for CdSe, increasing from 78.2 to $160.6 \Omega \mathrm{cm} ;^{2}$ for ZCISe, increasing from 72.4 to $141.8 \Omega \mathrm{cm}^{2}$ ). These results indicate that the charge recombination from photoanode to oxidation species (herein $\mathrm{S}_{n}{ }^{2-}$ ) of electrolyte at photoanode/electrolyte interfaces is effectively suppressed by the PEG additives, and the extent is strengthened with the increase of PEG $M_{\mathrm{w}}$. Therefore, an increase of $V_{\text {oc }}$ can be observed in the corresponding cell devices.

The mechanism for the observed retarded charge recombination is due to the adherence of PEG molecules on photoanode surface. This is because the presence of terminal hydroxyl groups and ether bonding oxygen atoms in the PEG molecules, which have strong coordinating capacity to $\mathrm{TiO}_{2}$ substrate. ${ }^{33,51}$ The adsorbed PEG molecules act as a passivation layer and an insulating energetic barrier layer, which prevent the direct contact of electrons on the surface of photoanode and electrolyte in the aspect of stereoscopic space and energetic field, and therefore inhibit the charge recombination processes through the surface defects in photoanode or with oxidation species in electrolyte. ${ }^{16}$ With the increase of $M_{\mathrm{w}}$ of PEG additives, the insulating feature, as shown in Tables 1-4, become intensified. Simultaneously, stereoscopic shielding effect has also been improved with the increase of $M_{\mathrm{w}}$. The increased insulating property combined with the improved stereoscopic shielding effect result in better barrier effect in isolating photogenerated electrons on photoanode surface with redox couple in the electrolyte, and therefore inhibiting the charge recombination 


\section{CdSe QDSC}
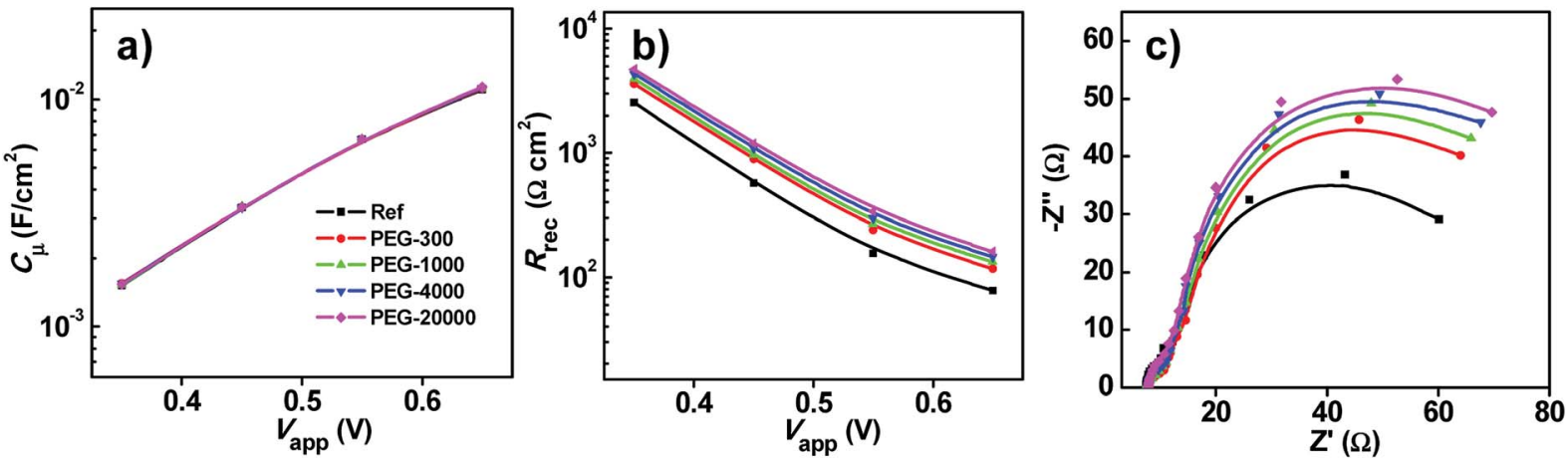

\section{ZCISe QDSC}
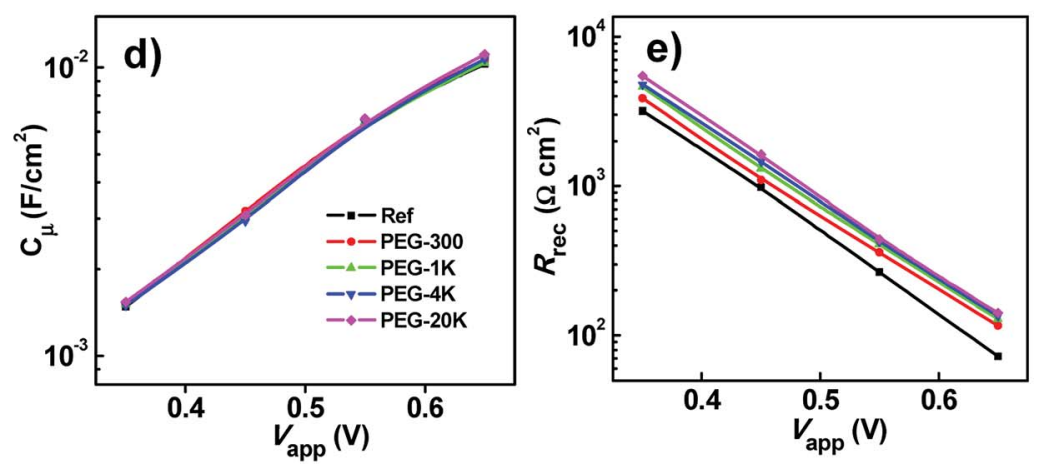

Fig. 2 EIS characterizations of CdSe (up), and ZCISe (bottom) QDSCs with electrolyte containing different PEG additives: (a and d) chemical capacitance $C_{\mu}$ (b and e) recombination resistance $R_{\text {rec, }}$, dependent on applied voltage $V_{\mathrm{app}}$, and (c and f) Nyquist plots under forward bias of $-0.65 \mathrm{~V}$

Table 3 Resistance $(R)$ and capacitance $(C)$ values for full cell devices corresponding to different PEG modified electrolyte systems under forward bias of $-0.65 \mathrm{~V}$

\begin{tabular}{lllll}
\hline QDSCs & PEG additives & $R_{\mathrm{s}}\left(\Omega \mathrm{cm}^{2}\right)$ & $R_{\text {rec }}\left(\Omega \mathrm{cm}^{2}\right)$ & $C_{\mu}\left(\mathrm{mF} \mathrm{cm}^{-2}\right)$ \\
\hline \multirow{2}{*}{ CdSe } & Ref. & 7.6 & 78.2 & 11.0 \\
& PEG-300 & 7.8 & 117.1 & 11.2 \\
& PEG-1K & 7.9 & 132.6 & 11.2 \\
& PEG-4K & 7.8 & 145.6 & 11.2 \\
& PEG-20K & 7.8 & 160.6 & 11.3 \\
ZCISe & Ref. & 6.8 & 72.4 & 10.3 \\
& PEG-300 & 7.1 & 116.2 & 10.7 \\
& PEG-1K & 7.4 & 128.9 & 10.4 \\
& PEG-4K & 7.2 & 135.3 & 10.7 \\
& PEG-20K & 7.4 & 141.8 & 11.1
\end{tabular}

Table 4 EIS parameters for symmetric dummy cells corresponding to electrolyte solutions containing different PEG additives, and the conductivity feature of the electrolyte solutions

\begin{tabular}{lllll}
\hline PEG additives & $R_{\mathrm{s}} \Omega \mathrm{cm}^{2}$ & $R_{1} \Omega \mathrm{cm}^{2}$ & $R_{\mathrm{ct}} \Omega \mathrm{cm}^{2}$ & $\begin{array}{l}\text { Conductivity } \\
\mathrm{mS} \mathrm{cm}\end{array}$ \\
\hline Ref. & 0.33 & 0.84 & 4.42 & 82.5 \\
PEG-300 & 0.39 & 0.55 & 2.87 & 59.1 \\
PEG-1K & 0.38 & 0.55 & 3.03 & 58.4 \\
PEG-4K & 0.72 & 1.34 & 10.63 & 45.0 \\
PEG-20K & 1.02 & 1.54 & 12.30 & 39.8
\end{tabular}

process more effective. This can give a reasonable explanation for the enhancement of charge recombination resistance value with the increase of $M_{\mathrm{w}}$ of PEG additives in electrolyte solutions as observed in Fig. $2 \mathrm{~b}$, e and Table 3 . The reason for the decrease of overall photovoltaic performance of cell devices with the increase of $M_{\mathrm{w}}$ of PEG additives can be ascribed to the decrease of electric conductivity of corresponding electrolyte systems as shown in Table 4 . The decrease of conductivity is mainly derived from the lower diffusion coefficient for higher $M_{\mathrm{w}}$ PEG. The conductivity $(\sigma)$ of an electrolyte solution is defined by the equation:

$$
\sigma=\sum_{\mathrm{i}}\left|Z_{\mathrm{i}}\right| F c_{\mathrm{i}} D_{\mathrm{i}}
$$

where $Z_{\mathrm{i}}, c_{\mathrm{i}}$ and $D_{\mathrm{i}}$ are the charge, concentration, diffusion coefficient of the conducting ions, and $F$ is the Faraday constant. Since the role of electrolyte in a cell device is responsible for the charge transport shuttling between photoanode and CE, the conductivity of the electrolyte would have a direct influence on the generation of electricity, and therefore on overall photovoltaic performance of the cell device. The poor ionic conductivity of the electrolyte with high $M_{\mathrm{w}}$ PEG additives deteriorates the performance of the resultant devices. In the tradeoff between the recombination resistance and conductivity, the electrolyte with low $M_{\mathrm{w}}$ PEG (PEG-300, and PEG-1K) showed the best performance, as shown in Fig. $2 d$, Tables 1 and 2 . 


\section{Impedance spectroscopy of symmetric dummy cells}

Since all kinds of PEG additives can suppress the charge recombination dynamics occurring at photoanode/electrolyte interface and bring forward an enhancement of $V_{\text {oc }}$ value in the resulting cell devices, the question of what causes the different effects on FF value for both CdSe and ZCISe QDSCs by PEG additives in electrolyte comes naturally. Generally, the FF in a sensitized solar cell is largely affected by the internal series resistance of the cell device, which includes various components for photoelectrochemical generation. Among these resistances, the charge transfer resistance $R_{\mathrm{ct}}$ at the counter electrode/electrolyte interface seems more severe than the ohmic resistance of the charge collection electrode and the resistances associated with the charge carrier transport by the electrolyte and $\mathrm{TiO}_{2}$ matrix. ${ }^{\mathbf{1 0}, 48}$ Since identical charge collection electrodes and $\mathrm{TiO}_{2}$ matrix were used in different cell systems, there should be no resistance difference in these components. Therefore, the main difference of internal resistance in difference systems should be the charge transfer resistance at $\mathrm{CE}$ / electrolyte interface, which is derived from the different compositions of the electrolyte solutions. Therefore, in the investigated systems, FF is mainly determined by the $R_{\mathrm{ct}}$ values.

In order to explore the origin of different FF values in cell devices, EIS measurements were carried out using symmetric dummy cells consisting of two identical $\mathrm{Cu}_{2} \mathrm{~S} /$ brass CEs placed face to face in a sandwich configuration and filling with polysulfide electrolyte solutions containing different PEG additives. The configuration of symmetric form can rule out the interference from photoanode and simply the measurement and analysis. ${ }^{52}$ The obtained Nyquist curves corresponding to different PEG additive systems are shown in Fig. 3a. As expected, Nyquist plots for each electrolyte system consist of two semicircles, which are related to the resistance and capacitance $\left(R_{1}\right.$ and $\left.C_{1}\right)$ of the solid-solid contact between $\mathrm{Cu}_{2} \mathrm{~S}$ catalytic materials and brass substrate, and charge transfer resistance and capacitance $\left(R_{\mathrm{ct}}\right.$ and $\left.C\right)$ at the CE/electrolyte interface, respectively. ${ }^{53-55}$ The high frequency intercept on the real axis corresponds to the series resistance $\left(R_{\mathrm{S}}\right)$. These three parameters are related to the contact of electrode substrate and catalytic material, the catalytic activity of $\mathrm{CE}$ catalytic materials, and conductivity of electrode and electrolyte. Standard equivalent circuit as reported in literature are used to extract the EIS data from the Nyquist plots, ${ }^{53}$ and key parameters including $R_{\mathrm{s}}, R_{1}$, and $R_{\mathrm{ct}}$ are listed in Table 4 . Owing to the outstanding conductivity of the brass substrate, the $R_{\mathrm{S}}$ values of all CE systems are small, but with the increase of $M_{\mathrm{w}}$ of PEG additives, the corresponding $R_{\mathrm{S}}$ values increase systematically (from 0.33 to $1.02 \Omega \mathrm{cm}^{2}$ ) in comparison with reference sample without the presence of any PEG additives. The observed increase of $R_{\mathrm{S}}$ value should be ascribed to the decrease of electrical conductivity with the introduction of insulating PEG additives, especially with the increase of $M_{\mathrm{w}}$, as shown in Table 4.

With the introduction of low $M_{\mathrm{w}}$ PEG-300, and PEG-1K in the electrolyte solution, charge transfer resistance $\left(R_{\mathrm{ct}}\right)$ at $\mathrm{CE} /$ electrolyte interface decreased remarkably (from 4.42 to 2.87 , and $3.03 \Omega \mathrm{cm}^{2}$ ). In contrast, the introduction of high $M_{\mathrm{w}}$ PEG$4 \mathrm{~K}$, and PEG-20K led to a significant increase of $R_{\mathrm{ct}}$ value (10.63, and $12.30 \Omega \mathrm{cm}^{2}$ ). Generally, $R_{\mathrm{ct}}$ can significantly influence the cell performance from two aspects. First, $R_{\mathrm{ct}}$ is considered to be a major hurdle in attaining a high FF value as stated in the above section. Second, $R_{\mathrm{ct}}$ is directly related to the reaction barrier of redox couple reduction reaction at the $\mathrm{CE} /$ electrolyte interface and hence plays a significant effect on the electrocatalytic properties of the catalyst. ${ }^{\mathbf{1 0 , 4 8 , 5 4}}$ High $R_{\text {ct }}$ value means slow charge transfer rate at the counter electrode. This leads to a high overpotential for the redox couple reduction reaction and creates a bottleneck for the electron flowing from CE to electrolyte, thereby promoting back electron transfer at the photoanode. These effects would result in a low $J_{\text {sc }}$ and FF for the corresponding cell devices. ${ }^{10,11}$

\section{Origin of the PEG additives effect difference between CdSe and ZCISe QDSCs}

The origin of the decrease of the CE/electrolyte charge transfer resistance by the introduction of PEG additives should be
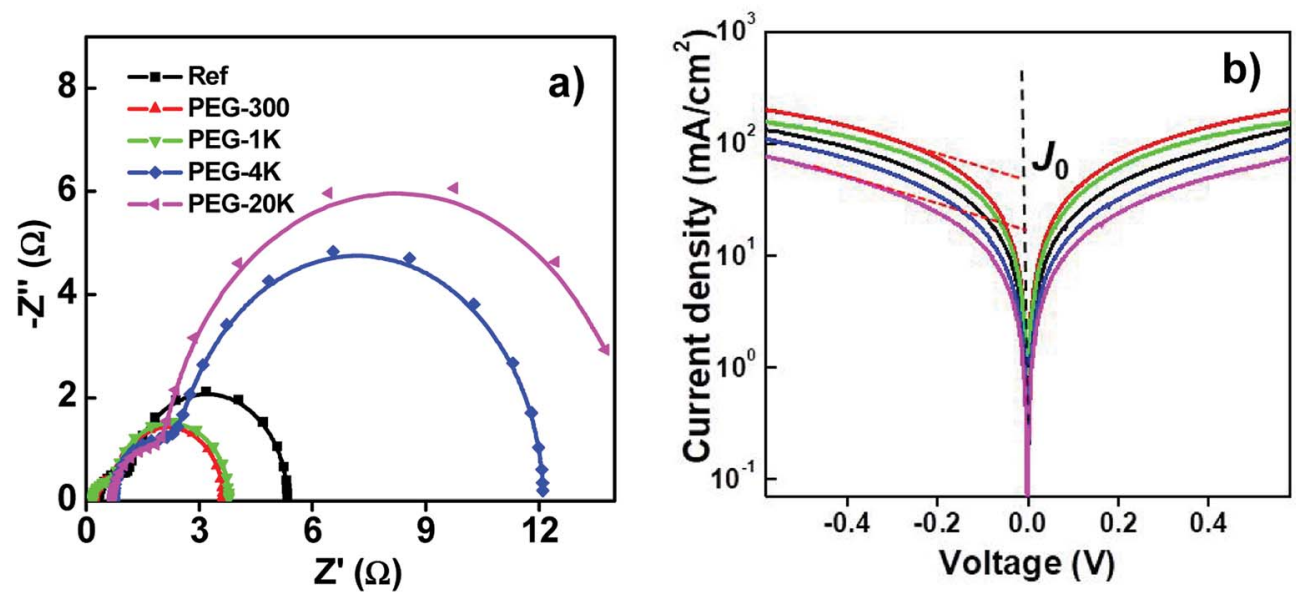

Fig. 3 Electrochemical characterizations of symmetric dummy cells corresponding to electrolyte containing different PEG additives: (a) Nyquist curves, (b) Tafel polarization curves. 
ascribed to the surfactant feature of this kind of polymer, which wets the surface of the CE catalytic materials and favors the close contact between $\mathrm{CE}$ and electrolyte, and therefore facilitates the catalytic reduction reaction of the redox couple and promotes the charge transfer from CE to electrolyte. With the increase of $M_{\mathrm{w}}$, the adherence of PEG on CE surface together with the electrical insulating feature of the PEG polymer impede the transfer of electron from $\mathrm{CE}$ to electrolyte and therefore increase the $R_{\mathrm{ct}}$ value and deteriorate the photovoltaic performance, especially the FF and $J_{\mathrm{sc}}$ values as observed in the $J-V$ measurement results.

To further verify the effects of PEG additives in the polysulfide electrolyte on photovoltaic performance of cell devices, Tafel-polarization measurements were also employed in a dummy cell configuration identical to the one used in EIS measurements. The obtained Tafel curves with logarithmic current density $(\log J)$ as a function of the applied voltage are shown in Fig. 3b. We can find that with the introduction of low $M_{\mathrm{W}}$ PEG (PEG-300, and PEG-1K) additives into the electrolyte systems, both the cathodic and anodic branches of the Tafel curves exhibit a larger slope in comparison with those for reference sample, demonstrating a higher exchange current density $\left(J_{0}\right)$ on the corresponding $\mathrm{CE}$ surface. This also indicates that the catalytic reduction of $\mathrm{S}_{n}{ }^{2-}$ to $\mathrm{S}^{2-}$ is accelerated at CE/ electrolyte interface. While the presence of high $M_{\mathrm{W}}$ PEG (PEG-4K, and PEG-20K) additives in the polysulfide electrolyte plays an inverse effect, resulting in a lower $J_{0}$ value, and therefore slowing the catalytic reduction of redox couples. Since $J_{0}$ is inversely proportional to the $R_{\mathrm{ct}}$ as defined by $J_{0}=R T / n F R_{\mathrm{ct}}{ }^{56}$ the observed variation trend for $J_{0}$ obtained in Tafel polarization measurements is in agreement with that of $R_{\mathrm{ct}}$ in EIS measurements. This gives a further support for the observed increase of $\mathrm{FF}$, and $J_{\mathrm{sc}}$ for the resultant QDSCs corresponding to polysulfide electrolyte containing low $M_{\mathrm{w}}$ PEG additives.

Based on the above data, we can understand that the positive effects for PEG-300, and PEG-1K additives, and the negative effect for PEG-20K additives on the photovoltaic performance of QDSCs. However, the results for PEG-20K additive on CdSe and ZCISe cells are different. What is the cause for this difference? Based on previous literature data, ${ }^{\mathbf{1 8 , 5 7}}$ the conduction band edge energy $\left(V_{\mathrm{CB}}\right)$ for the adopted $5.2 \mathrm{~nm}$ CdSe QDs is higher by $0.32 \mathrm{eV}$ in comparison with the investigated $4.1 \mathrm{~nm}$ ZCISe QDs. For clarity, the energy level diagrams of investigated CdSe and ZCISe together with $\mathrm{TiO}_{2}$ substrate are schematically illustrated in Fig. 4.

It is well established that this energy difference between QD and $\mathrm{TiO}_{2}$ serves as the driving force to ensure the effective injection of photo-generated electron from light absorber QD to $\mathrm{TiO}_{2}$ substrate. ${ }^{\mathbf{1 3 - 1 5 , 5 8 , 5 9}}$ In the construction of high efficiency QDSC, a higher $V_{\mathrm{CB}}$ of QDs relative to that of $\mathrm{TiO}_{2}$ electron acceptor is a prerequisite for QD sensitizers. The fact that the higher energy difference is accompanied with a greater electron injection rate $\left(K_{\mathrm{et}}\right)$ from QD to $\mathrm{TiO}_{2}$ electron acceptor has been well studied in previous reports. ${ }^{15,18,58}$ Meanwhile, the greater $K_{\text {et }}$ value can brings forward not only greater photocurrent, but also more effective transfer of photogenerated electrons through the photoanode film, and from external circuit to

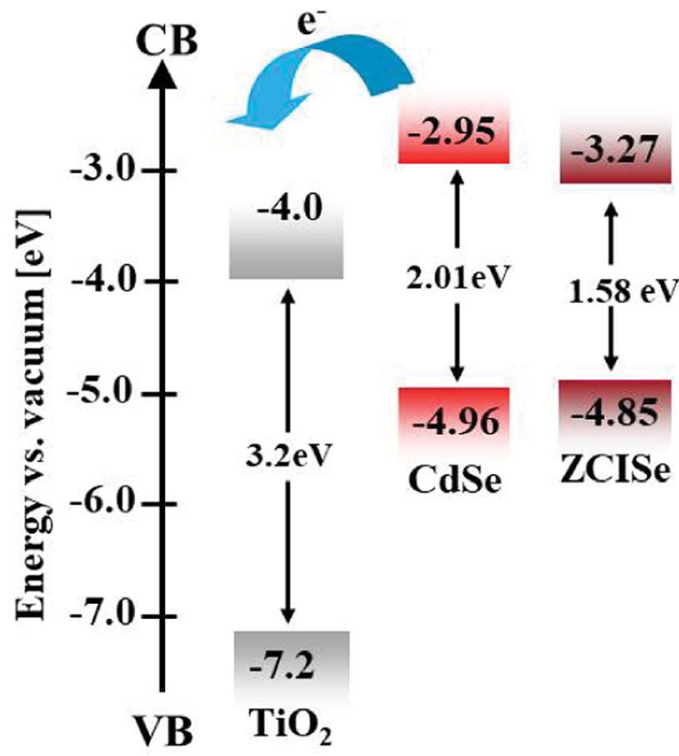

Fig. 4 Energy level diagram of $\mathrm{TiO}_{2}$ substrate, $5.2 \mathrm{~nm} \mathrm{CdSe}$, and $4.1 \mathrm{~nm}$ ZCISe QDs.

electrolyte via CE. This means that higher $V_{\mathrm{CB}}$ in QD light absorber would favor $V_{\mathrm{oc}}$, and $\mathrm{FF}$ of the resulting QDSCs. Therefore, the relatively high $V_{\mathrm{CB}}$ in CdSe QDs would offset the negative effects by high $M_{\mathrm{w}}$ PEG additive in electrolyte, and ensure high $V_{\text {oc }}$ and FF values in the resultant QDSCs. In fact, literature results have well demonstrated that with the enhancement of $V_{\mathrm{CB}}$ via alloying process, the $V_{\mathrm{oc}}$ and FF values in the $\mathrm{Zn}-\mathrm{Cu}-\mathrm{In}-\mathrm{S}$, and $\mathrm{Zn}-\mathrm{Cu}-\mathrm{In}-\mathrm{Se}$ based QDSCs are remarkably higher than those of $\mathrm{Cu}-\mathrm{In}-\mathrm{S}$, and $\mathrm{Cu}-\mathrm{In}-\mathrm{Se}$ QDSCs. ${ }^{18,60}$

\section{Conclusions}

In summary, the origin for the effects of different $M_{\mathrm{w}}$ PEG additives in polysulfide electrolyte on the performance of QDSCs has been explored. Furthermore, a facile and general route for remarkably improving photovoltaic performance of QDSCs is achieved with introduction of low $M_{\mathrm{w}}$ PEG additives into the polysulfide electrolyte. The energetic barrier effect due to the insulating feature together with the passivation effect on photoanode surface from PEG additives bring forward the suppression of charge recombination at photoanode/electrolyte interface, accompanied with the improvement of $V_{\text {oc }}$ of the resultant cell device. The wetting effect of the PEG surfactant reduces the charge transfer resistance at EC/electrolyte interface, and results in the improvement of FF and $J_{\mathrm{sc}}$. The intensified insulating feature with the increase of $M_{\mathrm{w}}$ of PEG favors the $V_{\mathrm{oc}}$ value, but has a negative effect on $\mathrm{FF}$ and $J_{\mathrm{sc}}$ for the resulting cell devices. Due to the relative high conduction band edge of CdSe light absorber, the negative effect on FF by high $M_{\mathrm{w}}$ PEG additive in ZCISe QDSCs is not realized in CdSe QDSCs.

\section{Conflicts of interest}

There are no conflicts to declare. 


\section{Acknowledgements}

This research is supported by the National Natural Science Foundation of China (NFSC No. 51732004, 91433106, and 21703071)

\section{References}

1 K. W. J. Barnham, M. Mazzer and B. Clive, Nat. Mater., 2006, 5, 161-164.

2 H. Tada, M. Fujishima and H. Kobayashi, Chem. Soc. Rev., 2011, 40, 4232-4243.

3 I. Mora-Sero and J. Bisquert, J. Phys. Chem. Lett., 2010, 1, 3046-3052.

4 J. Duan, H. Zhang, Q. Tang, B. He and L. Yu, J. Mater. Chem. A, 2015, 3, 17497-17510.

5 R. Wang, Y. Shang, P. Kanjanaboos, W. Zhou, Z. Ning and E. H. Sargent, Energy Environ. Sci., 2016, 9, 1130-1143.

6 P. V. Kamat, Acc. Chem. Res., 2012, 45, 1906-1915.

7 G. H. Carey, A. L. Abdelhady, Z. Ning, S. M. Thon, O. M. Bakr and E. H. Sargent, Chem. Rev., 2015, 115, 12732-12763.

8 A. J. Nozik, M. C. Beard, J. M. Luther, M. Law, R. J. Ellingson and J. C. Johnson, Chem. Rev., 2010, 110, 6873-6890.

9 J. B. Sambur, T. Novet and B. A. Parkinson, Science, 2010, 330, 63-66.

10 J. G. Radich, R. Dwyer and P. V. Kamat, J. Phys. Chem. Lett., 2011, 2, 2453-2460.

11 S. Jiao, J. Du, Z. Du, D. Long, W. Jiang, Z. Pan, Y. Li and X. Zhong, J. Phys. Chem. Lett., 2017, 8, 559-564.

12 Q. Zhang, X. Guo, X. Huang, S. Huang, D. Li, Y. Luo, Q. Shen, T. Toyoda and Q. Meng, Phys. Chem. Chem. Phys., 2011, 13, 4659-4667.

13 P. K. Santra and P. V. Kamat, J. Am. Chem. Soc., 2012, 134, 2508-2511.

14 J. Wang, I. Mora-Seró, Z. Pan, K. Zhao, H. Zhang, Y. Feng, G. Yang, X. Zhong and J. Bisquert, J. Am. Chem. Soc., 2013, 135, 15913-15922.

15 Z. Pan, I. Mora-Seró, Q. Shen, H. Zhang, Y. Li, K. Zhao, J. Wang, X. Zhong and J. Bisquert, J. Am. Chem. Soc., 2014, 136, 9203-9210.

16 K. Zhao, Z. Pan, I. Mora-Seró, E. Cánovas, H. Wang, Y. Song, X. Gong, J. Wang, M. Bonn, J. Bisquert and X. Zhong, J. Am. Chem. Soc., 2015, 137, 5602-5609.

17 J. Y. Kim, J. Yang, J. H. Yu, W. Baek, C. H. Lee, H. J. Son, T. Hyeon and M. J. Ko, ACS Nano, 2015, 9, 11286-11295.

18 J. Du, Z. Du, J. Hu, Z. Pan, Q. Shen, J. Sun, D. Long, H. Dong, L. Sun, X. Zhong and L. Wan, J. Am. Chem. Soc., 2016, 138, 4201-4209.

19 W. Wang, W. Feng, J. Du, W. Xue, L. Zhang, L. Zhao, Y. Li and X. Zhong, Adv. Mater., 2018, 30, 1705746.

20 I. Mora-Seró, S. Giménez, T. Moehl, F. Fabregat-Santiago, T. Lana-Villareal, R. Gómez and J. Bisquert, Nanotechnology, 2008, 19, 424007.

21 Y. Li, L. Zhao, Z. Du, J. Du, W. Wang, Y. Wang, L. Zhao, X. Cao and X. Zhong, J. Mater. Chem. A, 2018, 6, 2129.

22 L. Zhao, L. Zhao, W. Xue, W. Fang, Y. Wang and Y. Li, Sol. Energy, 2018, 169, 505.
23 W. Li and X. Zhong, J. Phys. Chem. Lett., 2015, 6, 796-806.

24 H. Zhu, N. Song and T. Lian, J. Am. Chem. Soc., 2013, 135, 11461-11464.

25 J. Y. Cong, X. C. Yang, L. Kloo and L. C. Sun, Energy Environ. Sci., 2012, 5, 9180-9194.

26 C. H. Chang and Y. L. Lee, Appl. Phys. Lett., 2007, 91, 053503.

27 H. Lee, M. K. Wang, P. Chen, D. R. Gamelin, S. M. Zakeeruddin, M. Gratzel and M. K. Nazeeruddin, Nano Lett., 2009, 9, 4221-4227.

28 S. Y. Chae, Y. J. Hwang and O. S. Joo, RSC Adv., 2014, 4, 26907-26911.

29 Z. Ning, C. Yuan, H. Tian, Y. Fu, L. Li, L. Sun and H. Agren, J. Mater. Chem., 2012, 22, 6032-6037.

30 L. Li, X. Yang, J. Gao, H. Tian, J. Zhao, A. Hagfeldt and L. Sun, J. Am. Chem. Soc., 2011, 133, 8458-8460.

31 T. Shu, X. Li, Z. L. Ku, S. Wang, S. Wu, X. H. Jin and C. D. Hu, Electrochim. Acta, 2014, 137, 700-704.

32 V. Jovanovski, V. González-Pedro, S. Giménez, E. Azaceta, G. Cabañero, H. Grande, R. Tena-Zaera, I. Mora-Seró and J. Bisquert, J. Am. Chem. Soc., 2011, 133, 20156-20159.

33 J. Du, X. Meng, K. Zhao, Y. Li and X. Zhong, J. Mater. Chem. A, 2015, 3, 17091-17097.

34 G. Jiang, Z. Pan, Z. Ren, J. Du, C. Yang, W. Wang and X. Zhong, J. Mater. Chem. A, 2016, 4, 11416-11421.

35 J. Yu, W. Wang, Z. Pan, J. Du, Z. Ren, W. Xue and X. Zhong, J. Mater. Chem. A, 2017, 5, 14124-14133.

36 H. Wei, G. Wang, J. Shi, H. Wu, Y. Luo, D. Li and Q. Meng, J. Mater. Chem. A, 2016, 4, 14194-14203.

37 W. Feng, Y. Li, J. Du, W. Wang and X. Zhong, J. Mater. Chem. A, 2016, 4, 1461-1468.

38 W. Feng, L. Zhao, J. Du, Y. Li and X. Zhong, J. Mater. Chem. A, 2016, 4, 14849-14856.

39 H. Kim, I. Hwang and K. Yong, ACS Appl. Mater. Interfaces, 2014, 6, 11245-11253.

40 Z. Yu, Q. Zhang, D. Qin, Y. Luo, D. Li, Q. Shen, T. Toyoda and Q. Meng, Electrochem. Commun., 2010, 12, 1776-1779.

41 H. Chen, L. Lin, X. Yu, K. Qiu, X. Lu, D. Kuang and C. Su, Electrochim. Acta, 2013, 92, 117-123.

42 M. C. Sekhar, K. Santhosh, J. P. Kumar, N. Mondal and S. Soumya, J. Phys. Chem. C, 2014, 118, 18481-18487.

43 M. Shalom, S. Ruhle, I. Hod, S. Yahav and A. Zaban, J. Am. Chem. Soc., 2009, 131, 9876-9877.

44 E. M. Barea, M. Shalom, S. Giménez, I. Hod, I. Mora-Seró, A. Zaban and J. Bisquert, J. Am. Chem. Soc., 2010, 132, 6834-6839.

45 S. R. Raga, E. M. Barea and F. Fabregat-Santiago, J. Phys. Chem. Lett., 2012, 3, 1629-1634.

46 X. Zhong, Y. Feng and Y. Zhang, J. Phys. Chem. C, 2007, 111, 526-531.

47 Z. Du, H. Zhang, H. Bao and X. Zhong, J. Mater. Chem. A, 2014, 2, 13033-13040.

48 I. Mora-Seró, S. Gimenez, F. Fabregat-Santiago, R. Gomez, Q. Shen, T. Toyoda and J. Bisquert, Acc. Chem. Res., 2009, 42, 1848-1857.

49 F. Fabregat-Santiago, G. Garcia-Belmonte, I. Mora-Seró and J. Bisquert, Phys. Chem. Chem. Phys., 2011, 13, 9083-9118. 
50 V. González-Pedro, X. Xu, I. Mora-Seró and J. Bisquert, ACS Nano, 2010, 4, 5783-5790.

51 B. Ballou, B. C. Lagerholm, L. A. Ernst, M. P. Bruchez and A. S. Waggoner, Bioconjugate Chem., 2004, 15, 79-86.

52 W. Kwon, J. M. Kim and S. W. Rhee, J. Mater. Chem. A, 2013, 1, 3202-3215.

53 Y. Yang, L. Zhu, H. Sun, X. Huang, Y. Luo, D. Li and Q. Meng, ACS Appl. Mater. Interfaces, 2012, 4, 6162-6168.

54 J. Bisquert, D. Cahen, G. Hodes, S. Rühle and A. Zaban, J. Phys. Chem. B, 2004, 108, 8106-8118.

55 T. N. Murakami, S. Ito, Q. Wang, M. K. Nazeeruddin, T. Bessho, I. Cesar, P. Liska, R. Humphry-Baker, P. Comte,
P. Péchy and M. Graetzel, J. Electrochem. Soc., 2006, 153, A2255.

56 I. Hwang and K. Yong, ChemElectroChem, 2015, 2, 634-653.

57 R. W. Meulenberg, J. R. I. Lee, A. Wolcott, J. Z. Zhang, L. J. Terminello and T. van Buuren, ACS Nano, 2009, 3, 325-330.

58 I. Robel, M. Kuno and P. V. Kamat, J. Am. Chem. Soc., 2007, 129, 4136-4137.

59 J. H. Bang and P. V. Kamat, ACS Nano, 2009, 3, 1467-1476.

60 L. Yue, H. S. Rao, J. Du, Z. X. Pan, J. Yu and X. H. Zhong, RSC Adv., 2018, 8, 3637-3645. 